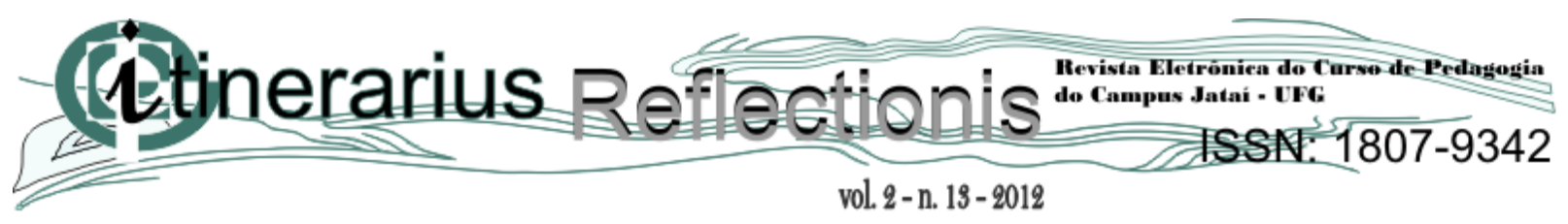

\title{
REFLEXÃO SOBRE O ENSINO DE MATEMÁTICA NOS ANOS INICIAIS DO ENSINO FUNDAMENTAL: AS TECNOLOGIAS NO ESPAÇO DA SALA DE AULA
}

\author{
Valéria Gomes da SILVA \\ Mestranda em Educação - FACED/UFU \\ gomesvaleria@hotmail.com \\ Guilherme Saramago de OLIVEIRA \\ Professor da Faculdade de Educação - FACED/UFU \\ Programa de Pós-Graduação em Educação \\ Universidade Federal de Uberlândia
}

RESUMO: Este estudo tem como objetivo refletir sobre a prática educativa de professores de Matemática dos primeiros anos do Ensino Fundamental, além de discutir as tecnologias como uma alternativa metodológica nos processos de ensino e aprendizagem. Atualmente a prática pedagógica predominante em Matemática, no espaço da sala de aula, é a tradicional, cujos papeis do professor é transmitir os conteúdos e do aluno é de receber e acatar as informações, além de reproduzir os saberes expostos pelo docente. A partir disso, entendemos que muitos dos problemas presentes nos processos de ensino e aprendizagem de Matemática são decorrentes da metodologia desenvolvida pelos docentes. No entanto, de maneira geral, é fundamental uma reflexão sobre a metodologia desenvolvida pelo professor no que diz respeito aos recursos didáticos utilizados por ele, pois nas escolas, o docente ainda utiliza muito a lousa, giz ou pincel e o livro didático. Com o avanço das tecnologias na sociedade foi iniciada a inserção delas em muitas escolas da Educação básica, possibilitando aos docentes novas alternativas de recursos didáticos no ensino. Portanto, as tecnologias no ensino de Matemática podem ser uma alternativa que propiciará ao aluno a construção de novos saberes, mas para isso é necessário que o professor esteja preparado para desenvolver as atividades pedagógicas utilizando as Tecnologias de Informação e Comunicação - TICs como um aparato que contribuirá de forma eficaz na aprendizagem de conteúdos da Matemática.

Palavras chave: Matemática; Tecnologias; Prática Pedagógica; Ensino Fundamental.

ABSTRACT: The aim of this work is to reflect the educational practice of mathematics
teachers in the early years of elementary school. In addition we discuss the technologies as an
alternative methodology for teaching and learning. Nowadays the predominant pedagogical
practice in mathematics in the classroom is the traditional teacher. The role of the traditional
teacher is to convey the content. The role of the students is to receive, heeding information,
and reproduce the knowledge exhibited by the teacher. From this, we understand that many of 


\section{Ctinerarius Refiectionis 20 \\ vol. 2-n. 19-2012

the problems present in the teaching and learning of mathematics are due to the methodology developed by the teachers. However, it is very important a critical reflection on the methodology developed by the teacher concerning to the educational resources used by them. In the schools, the teacher is still using blackboard, chalk and brush or textbook. With the advancement of technology in the society, it has started an insertion of it in many schools of basic education. This techological insertion in the schools has enabled the teachers to new teaching resources in alternative education. Therefore, the technologies in teaching mathematics can be an alternative that would provide to the student a construction of a new knowledge. Nevertheless this requires prepared teachers to develop educational activities using the Information and Communication Technologies - ICTs as an apparatus that contribute effectively in the learning of mathematics.

Keywords: Mathematics. Technologies. Pedagogical Practice. Elementary School

\section{Introdução}

Atualmente é fundamental refletirmos sobre como os professores têm desenvolvido suas práticas pedagógicas em relação aos conteúdos de Matemática no espaço da sala de aula. De maneira geral, sabe-se que o ensino de Matemática está mergulhado em diversos problemas relacionados às metodologias e técnicas desenvolvidas para a execução de conteúdos escolares.

A Matemática não é uma disciplina que muitos alunos estudam por considerarem interessante e envolvente. É muito comum encontrar em escolas da Educação básica, especificamente nos primeiros anos do Ensino Fundamental, discentes argumentando que não gostam de estudar conteúdos de Matemática porque não conseguem decorar a tabuada, não aprendem os conceitos da disciplina e não conseguem resolver os problemas matemáticos. Além disso, muitos julgam não saber para que precisam compreender determinados conteúdos da referida disciplina.

Esses problemas podem estar relacionados à maneira (não é necessário o de aqui) como o professor desenvolve os conteúdos. Na prática pedagógica os docentes de maneira geral, ensinam a Matemática por meio do método expositivo, sem a participação dos alunos. Estes se comportam como sujeitos passivos dos processos de ensino e aprendizagem, pois sua 


\section{(titinerarius 28 \\ Revista Eletróniéa do Curse de Pedagogia \\ do Campus Jataí - UFE \\ ISSN: $1807-9342$}

vol. 2-n. 13 - 2012

postura é somente de ouvir, acatar e reproduzir as informações divulgadas pelo professor. E no momento da avaliação o papel do aluno é reproduzir a fala do docente, sem ter a liberdade de desenvolver o raciocínio lógico-matemático na resolução de problemas.

Diante disso, como forma de amenizar estes problemas do ensino e aprendizagem de Matemática, propõe-se uma alternativa metodológica: trabalhar os conteúdos da referida disciplina utilizando as Tecnologias de Informação e Comunicação (TIC), que dependendo da forma como forem utilizadas nas práticas de ensino poderão contribuir na busca e elaboração do conhecimento de maneira eficaz.

Nesse sentido, no cenário educacional, discutir a questão das Tecnologias de Informação e Comunicação (TIC) no trabalho docente em espaço escolar é algo considerado relevante no mundo que está em constantes mudanças sociais, econômicas, políticas, culturais e educacionais.

Nota-se que as tecnologias vêm transformando as relações sociais de forma veloz modificando a interação e a comunicação entre o homem. Observa-se que as tecnologias estão presentes em todas as partes do espaço físico, seja numa empresa como nas bolsas de valores, em hospitais, em casa e é claro na educação escolar. Vale ressaltar, que a tecnologia não é resumida somente a computador, rádio, celular, vídeo-game e televisão. Segundo Kenski (2007) a tecnologia está em todos os ambientes, já faz parte do cotidiano do homem, pois, desde as atividades mais comuns como dormir, comer, trabalhar, nos deslocarmos para diferentes espaços físicos, ler e conversar são ações possíveis que acontecem devido ao acesso à tecnologia. "Tecnologias que resultaram, por exemplo, em lápis, cadernos, canetas, lousas, giz e muitos outros produtos, equipamentos e processos que foram planejados e construídos para que possamos ler, escrever, ensinar e aprender" ( p. 24).

Nessa discussão é fundamental esclarecer e apontar outras tecnologias que possivelmente estão presentes na escola. (Arruda, 2004, p. 80), relata que "a instituição educativa utiliza diversas tecnologias no seu interior, a própria escrita, a linguagem verbal, o saber simbólico e a construção de significados, assim como a própria instituição escolar representam exemplos de tecnologias".

Quando o professor se apropria das tecnologias em sala de aula, há possibilidades de esse profissional desenvolver os conteúdos de Matemática utilizando a tecnologia de 
maneira eficaz, mas isso dependerá da metodologia empregada por ele. É comum nas redes de ensino, muitos professores que estão habituados a desenvolverem a aula por meio do método expositivo ao tentarem modificar suas estratégias de ensino utilizando a tecnologia, começar a produzir e apresentar slides, e exibir filmes com uso das tecnologias, justificando assim a aula mais interessante e envolvente. A respeito da utilização das tecnologias nas instituições escolares Kenski (2007) assevera que:

Por mais que as escolas usem computadores e internet em suas aulas, estas continuam sendo seriadas, finitas no tempo, definidas no espaço restrito das salas de aula, ligadas a uma única disciplina e graduadas em níveis hierárquicos e lineares de aprofundamento dos conhecimentos em áreas específicas do saber (Kenski, 2007, p. 45).

De acordo com as ideias da autora o fato de simplesmente utilizar a tecnologia nas aulas como mera transmissão de conteúdos, sem estabelecer uma relação com o conhecimento sistematizado, de nada adiantará para a apropriação desse recurso tecnológico na busca de novos saberes. E, a fim de que o ensino com o uso das tecnologias seja produtivo é fundamental que o professor reflita sobre a importância, a inserção e a contribuição das tecnologias para desenvolver a aprendizagem significativa. Diante disso, o docente tem a possibilidade de desenvolver os conteúdos de Matemática de maneira eficaz, mas isso dependerá de como ele se apropria e envolve seus alunos nos processos de ensino e aprendizagem mediante as tecnologias.

É visível que a inserção das tecnologias no trabalho docente vem alterando a forma de comunicação entre os protagonistas dos processos de ensino e aprendizagem no cotidiano escolar, possibilitando outro modo de compreender/interpretar o mundo e entender as contribuições do uso do computador nas práticas educativas, considerando-o como um mediador amplo no processo educacional. Assim, não basta apenas inserir computadores nos espaços escolares para que existam mudanças efetivas nas estratégias didáticas e pedagógicas, pois de acordo com Arruda (2004) o aparato tecnológico possibilita criar ambientes de aprendizagem favorecendo o surgimento de novas maneiras de pensar e aprender. 


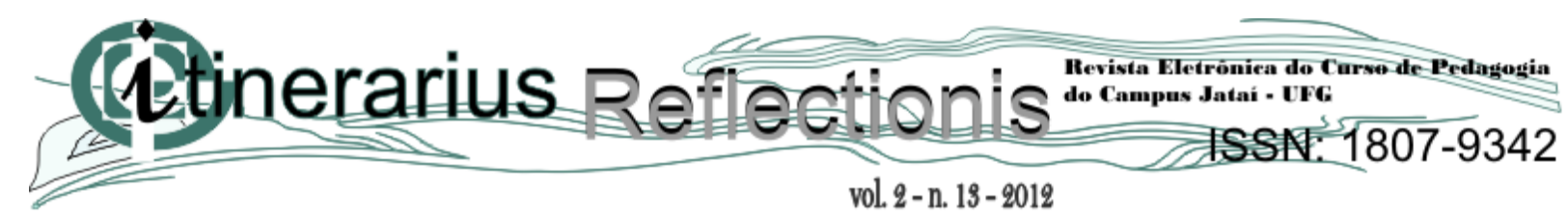

Nesse sentido, o objetivo desse trabalho é refletir sobre a prática educativa de professores de Matemática dos primeiros anos do Ensino Fundamental, além de discutir as tecnologias como uma alternativa metodológica nos processos de ensino e aprendizagem.

Considerações sobre a prática pedagógica no ensino de Matemática

A Matemática não se limita a cálculos, formas geométricas, teoremas, axiomas. Esta afirmação sintetiza que o estudo da Matemática vai além disso. A maneira, como vem sendo desenvolvidos conteúdos matemáticos é motivo de reflexão sobre a prática docente. Sobre o ensino de Matemática os Parâmetros Curriculares Nacionais (PCNs) (1997) afirmam:

[...] é importante que a Matemática desempenhe, equilibrada e indissociavelmente, seu papel na formação de capa cidades intelectuais, na estruturação do pensamento, na agilização do raciocínio dedutivo do aluno, na sua aplicação a problemas, situações da vida cotidiana e atividades do mundo do trabalho e no apoio à construção de conhecimentos em outras áreas curriculares (BRASIL, 1997, p. 25).

Para que haja a concretização significativa desses fatores dependerá das metodologias e estratégias de ensino utilizadas pelo professor, pois a prática pedagógica desenvolvida e predominante nas escolas não possibilita ao aluno desenvolver o raciocínio lógico-matemático, sendo esse aspecto decorrente da maneira como o professor desenvolve suas práticas educativas. Sabe-se que o ensino predominante em sala de aula é aquele em que o professor transmite o saber previamente pensado e planejado, por meio de exposição oral, enquanto o aluno se comporta como um sujeito passivo, fazendo repetições e cópias do que o professor fala.

Para Micotti (1999) as aulas expositivas,

Pretendem focalizar o saber, mas geralmente, ficam sem sentido para os alunos; os conteúdos via de regra, não se transformam em conhecimento devido sobretudo, à falta de oportunidade para os aprendizes elaborarem e manifestarem sua compreensão sobre os mesmos (MICOTTI, 1999, p. 161).

Esse método de ensino praticado pelos docentes permite entender que a Matemática é um conhecimento pronto e acabado, sem possibilidades de questionamentos e 
reflexões. Tal procedimento leva-nos a compreender que o professor está como sujeito central dos processos de ensino e aprendizagem. "A atividade matemática escolar não implica "olhar para coisas prontas e definitivas", mas a construção e a apropriação de um conhecimento pelo aluno, que se servirá dele para compreender e transformar sua realidade" (BRASIL, 1997, p. 19).

Dessa forma, sem que exista uma integração, um envolvimento do aluno nas práticas pedagógicas do cotidiano da sala de aula, o professor poderá formar um sujeito passivo, domesticado e dotado de limitações na produção do conhecimento. Para que esta barreira possa ser rompida é esperado que os professores os quais utilizam o método tradicional de ensino, possam rever, repensar e refletir sobre sua prática desenvolvida em sala de aula.

Os PCNs (1997) propõem que:

Recursos didáticos como jogos, livros, vídeos, calculadoras, computadores e outros materiais têm um papel importante no processo de ensino e aprendizagem. Contudo, eles precisam estar integrados a situações que levem ao exercício da análise e da reflexão, em última instância, a base da atividade matemática (BRASIL, 1997, p. 19).

No entanto, de modo geral, o professor tem várias opções de recursos de ensino para desenvolver conteúdos de Matemática, de modo que, as situações de ensino tornem - se, para o aluno, interessantes e envolventes, e possam possibilitar-lhes a chance de ser um sujeito ativo e participante das atividades pedagógicas desenvolvidas nas aulas de Matemática. E, para isso, aponta-se como alternativas de recurso de ensino as tecnologias.

As tecnologias como uma estratégia de ensino e aprendizagem na disciplina de Matemática, são algo considerado estimulante, interessante e dinâmico para muitos alunos que não se interessam e ou não gostam de Matemática, e também para os que gostam. É evidente que o recurso em si não irá alterar a qualidade do ensino, mas, sim, a maneira pela qual o professor e o aluno se apropriam da tecnologia e a manipulam na busca de novos conhecimentos.

Nesse sentido, acredita-se que as tecnologias mantêm relação com a construção do conhecimento e possuem influência motivadora no processo de ensino e aprendizagem, podendo contribuir para o desenvolvimento cognitivo do aluno. Ela é considerada como um 
elemento potencializador das capacidades humanas. Assim, a metodologia adotada pelo professor é fundamental para o desempenho do aluno, uma vez que o docente em seu oficio tem a função de fazer o estudante avançar em sua compreensão de mundo a partir de seu desenvolvimento já consolidado.

Desse modo, o educador é o profissional principal quando se trata de propostas para a inovação da prática pedagógica escolar, pois é ele quem investiga, pesquisa e elabora uma inovação com as tecnologias em sala de aula. Portanto, os conteúdos de Matemática podem tornar-se atraentes e prazerosos com o uso das tecnologias.

As tecnologias no contexto escolar

A utilização do computador no espaço escolar parece adquirir, gradualmente, um papel específico e relevante para a educação e para a formação do ser humano, embora muitas escolas da rede pública não se encontram adequadamente equipadas de computadores e acesso à internet. Além disso, pode haver professores que talvez não estejam preparados e qualificados para explorarem o computador em suas práticas educativas, pois não basta simplesmente inserir máquinas na escola, é necessário uma capacitação dos professores para a utilização eficaz das tecnologias, além desses nos processos de ensino e aprendizagem partirem da cultura digital do aluno nos espaços extra-escolares.

Atualmente as tecnologias parecem estar cada vez mais presentes na vida de muitas crianças, pois essas já nascem mantendo contato com a tecnologia, o que contribui para mudanças nos modos de comunicação e interação. Essas mudanças trazem alguns benefícios como o aumento da interatividade quando o aluno encontra-se diante do computador com um universo de informações contido na rede, mesmo que não envolva outra pessoa. Isso permite entender que o uso do computador possa contribuir de alguma maneira para a melhoria das condições de elaboração do conhecimento desde que seja utilizado de maneira adequada.

As ideias de Pais (2002) vão ao encontro destas discussões. Para o autor,

[...] existem tecnologias que favorecem mais diretamente a expansão das condições de elaboração do conhecimento. Estas se caracterizam pela 


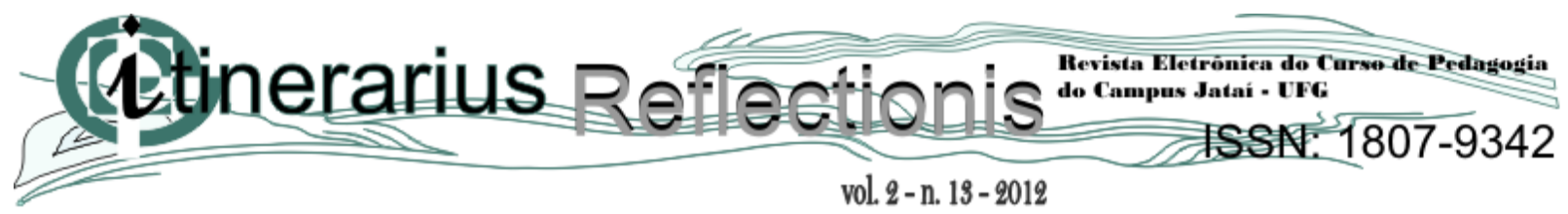

melhora das condições de aprendizagem e isto depende da maneira como ocorre a relação entre o usuário e as informações contidas no software utilizado. Tudo indica que quanto mais interativa for essa relação, maior será o significado do conhecimento para o sujeito (PAIS, 2002, p. 16)

Grinspun, (1999) salienta que:

Precisa-se hoje, de um pensamento que compreenda a tecnologia como parte de um momento histórico: a tecnologia é parte desta história e está interligada à formação e à construção do sujeito. "A tecnologia faz parte desse contexto não como algo de fora, mas como parte de um todo em que o homem cria, recria e se beneficia da sua própria realização e das demais colocadas na sociedade" (GRINSPUN, 1999, p. 19).

Percebe-se que a tecnologia (computador) está ligada à formação e à construção do indivíduo como afirma Ribeiro (2007). Partindo disso, o professor pode fazer escolhas de como poderá apropriar-se do uso do computador em suas práticas educativas, ou seja, a sua opção metodológica e a maneira como ele desenvolverá os conteúdos é fundamental para o bom andamento do ensino e da aprendizagem. Assim, é essencial que o professor compreenda o uso do computador como parte da cultura escolar, e para isso é necessário que ele se familiarize com a nova linguagem.

Ribeiro (2007) afirma:

No viés cultural, entendendo a cultura como rede de relações e de diversidade, espera-se que a tecnologia e a escola sejam fiéis à vida, sejam abertas e plurais. Há de se respeitar a diversidade e a pluralidade; há de se propiciar a comunicação entre os homens consigo mesmo, entre si e com o mundo que os cerca, não apenas preservando a individualidade, mas levando-se em consideração o coletivo. $O$ que se procura é o desenvolvimento geral dos sujeitos escolares, que seja no estabelecimento de novas relações, quer seja na capacidade de síntese, de organização e sistematização, expressando-se mediante múltiplas linguagens (incluindo-se a linguagem das novas tecnologias), numa interação ativa e crítica com o meio físico e social

(RIBEIRO 2007, p. 92).

É importante que como forma de compreender os novos caminhos da educação, o professor tente fazer parte desse mundo de constantes mudanças científicas e tecnológicas. Acredita-se que é de responsabilidade da escola, juntamente com o corpo docente, rever 


\section{Etinerarius Reflectionis

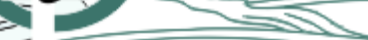 \\ vol. 2-n. 13-2012

meios e situações de ensino para que os alunos possam desenvolver seus potenciais de maneira produtiva sem acomodarem a receber informações passadas pelos educadores.

Leivas (2001) defende que:

O educador não deve entrar na sala de aula para "ensinar", mas, sim para "ajudar"os alunos a aprender.Nesse sentido, os computadores e suas diversas ferramentas podem representar, para o educador, uma gama enorme de novas possibilidades e atividades pedagógicas que poderão ser incorporadas com diversos objetivos, principalmente o de acender nos alunos o desejo de aprender a aprender, o entusiasmo pelo conhecimento e, principalmente, o prazer e a alegria da descoberta (LEIVAS 2001, p. 85)

Com a implantação das tecnologias educacionais no ambiente interno da escola, o professor passa a ser um dos principais responsáveis para lidar com as TICs no desenvolvimento das práticas pedagógicas, mas sabe-se que muitos não possuem preparação pedagógica para a utilização desse recurso, e isso é decorrente dos cursos de formação inicial nas áreas de licenciaturas plenas que não suprem as necessidades do graduando e do aluno egresso para desenvolverem metodologias de ensino que possam envolver o aparato tecnológico de modo que tal recurso seja utilizado pelo educador de forma significativa, a fim de avançar na construção de novos saberes. Nesse sentido, acredita-se que os futuros e os já atuantes docentes estão diante do desafio de lidar com as tecnologias no trabalho pedagógico.

No entanto, de modo geral, é emergente o professor compreender que não são somente os cursos de formação que darão subsídios no seu preparo para o uso das tecnologias em sala de aula. O ambiente escolar também é um espaço onde os docentes (despreparados para lidar com as TICs) têm a oportunidade de buscar formas de trabalhar utilizando o aparato tecnológico no ambiente educativo.

Leite (2010) entende que o papel do professor na escola de hoje deverá:

Estar comprometido com as crianças que finalmente conseguiram adentrar as escolas; ser capaz de desenvolver um trabalho docente de qualidade em uma escola para todos; ser um profissional com capacidade de inovação, de criação, de participação nos processos de tomada de decisões e de produção de conhecimentos, e não um simples técnico-reprodutor de conhecimentos e/ou monitor de programas pré-elaborados (LEITE, 2010, p. 172). 


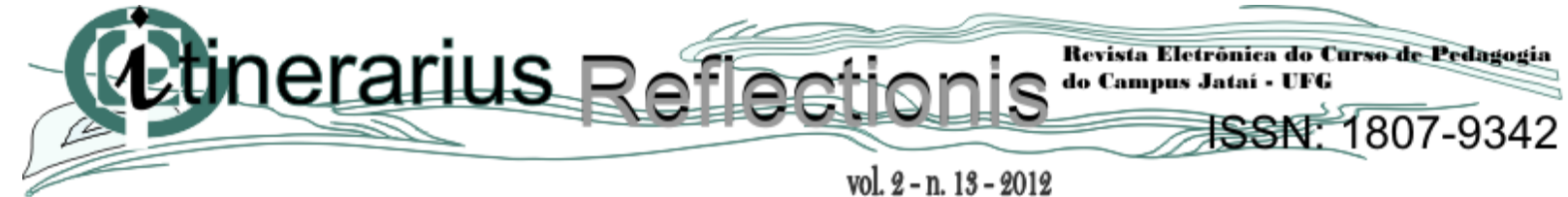

Quando a autora afirma que o professor deverá ser um profissional com capacidade de inovação e de criação, refletimos que, entre os meios existentes que podem contribuir para uma Educação de qualidade, é imprescindível que o docente, para desenvolver um ensino e uma aprendizagem capazes de favorecer a elaboração e construção do conhecimento de forma sistemática, busque por si mesmo metodologias de ensino que sejam condizentes com as tecnologias, não tornando o uso delas como uma mera reprodução de informação. "Ao se pensar o processo pedagógico mediado pela tecnologia, não se pode esquecer que a centralidade da ação deve estar nos sujeitos, e não na técnica” (RIBEIRO, 2007, p. 94).

Nesse sentido, é imprescindível que a instituição educadora juntamente com os docentes não se alheiem às modificações externas. Portanto, percebe-se que o professor está diante de um desafio com a inserção das TICs no seu trabalho pedagógico.

\section{Conclusão}

Sobre isso, no contexto da educação escolar em relação às TIC existem ainda muitos desafios para o professor em relação à utilização das tecnologias em seu trabalho, como uma alternativa metodológica para o desenvolvimento de conteúdos matemáticos.

Portanto, na sociedade atual, o contato dos seres humanos com as tecnologias tem alterado as maneiras de comunicação e interação entre eles. Dessa forma, o professor necessita acompanhar de perto as mudanças ocorridas, para que possa haver elaboração de estratégias de ensino e aprendizagem condizentes com as perspectivas inovadoras.

Nesse sentido, as tecnologias no ensino de Matemática podem ser um recurso didático que propiciará melhoras na aprendizagem do aluno. Além disso, o seu uso em sala de aula com certeza irá tornar o ensino mais dinâmico. Mas para isso vir à tona é necessário que o professor esteja apto para desenvolver as atividades pedagógicas utilizando as TICs como um aparato que contribuirá de forma eficaz na aprendizagem de conteúdos matemáticos. 


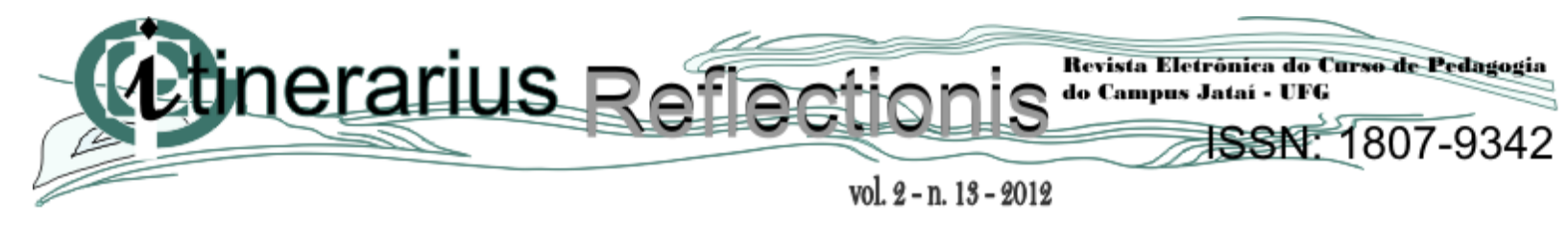

\section{REFERÊNCIAS}

ARRUDA, E. Ciberprofessor: novas tecnologias, ensino e trabalho docente. Belo Horizonte: Autêntica, 2004.

BRASIL. Ministério da Educação. Secretaria de Educação Fundamental. Parâmetros Curriculares Nacionais de Matemática. Brasília, MEC/SEF, 1997

GRINSPUN, M, P, S, Z. (Org.). Educação tecnológica: desafios e perspectivas. São Paulo: Cortez, 1999.

LEITE, Y. U. F. Como, onde e quando se formam os professores? In: GARCIA, R.L. (Org.). Diálogos Cotidianos. Petrópolis, RJ: DP et al. 2010. cap. 11, p. 169-185.

LEIVAS, M. "No olho do furacão": as novas tecnologias e a educação hoje. In: SILVA, M, L, S, da. (Org.). Novas Tecnologias: educação e sociedade na era da informação. Belo Horizonte: Autêntica, 2001. p. 73-89.

KENSKI, V. M. Educação e Tecnologias: o novo ritmo da informação. Campinas, SP: Papirus, 2007.

MICOTTI, M. C. de O. O ensino e as propostas pedagógicas. In: BICUDO, M. A. V. (Org.). Pesquisa em Educação Matemática: concepções e perspectivas. São Paulo: UNESP, 1999.

PAIS, L.C. Educação Escolar e as Tecnologias da Informática. Belo Horizonte: Autêntica, 2002.

RIBEIRO, O, J. Educação e novas tecnologias: um olhar para além da técnica. In: COSCARELLI, C.V; RIBEIRO, A. E. (Orgs.). Letramento digital: aspectos sociais e possibilidades pedagógicas. Belo Horizonte: Ceale; Autêntica, 2007. p. 85-97. 